\title{
Final Report: Flight Dynamics and Impact Characteristics of Thin Flyer Plates Driven by Laser- and Electrically- produced Plasmas
}

R.S. Lee, J. Colvin, A. Frank, L. Fried, J. Reaugh, and B. Remington

February 14, 2001 


\section{DISCLAIMER}

This document was prepared as an account of work sponsored by an agency of the United States Government. Neither the United States Government nor the University of California nor any of their employees, makes any warranty, express or implied, or assumes any legal liability or responsibility for the accuracy, completeness, or usefulness of any information, apparatus, product, or process disclosed, or represents that its use would not infringe privately owned rights. Reference herein to any specific commercial product, process, or service by trade name, trademark, manufacturer, or otherwise, does not necessarily constitute or imply its endorsement, recommendation, or favoring by the United States Government or the University of California. The views and opinions of authors expressed herein do not necessarily state or reflect those of the United States Government or the University of California, and shall not be used for advertising or product endorsement purposes.

This work was performed under the auspices of the U. S. Department of Energy by the University of California, Lawrence Livermore National Laboratory under Contract No. W-7405-Eng-48.

This report has been reproduced directly from the best available copy.

Available to DOE and DOE contractors from the

Office of Scientific and Technical Information

P.O. Box 62, Oak Ridge, TN 37831

Prices available from (423) 576-8401

http://apollo.osti.gov/bridge/

Available to the public from the National Technical Information Service

U.S. Department of Commerce 5285 Port Royal Rd., Springfield, VA 22161 http://www.ntis.gov/

OR

Lawrence Livermore National Laboratory Technical Information Department's Digital Library http://www.llnl.gov/tid/Library.html 


\title{
Final Report: Flight Dynamics and Impact Characteristics of Thin Flyer Plates Driven by Laser- and Electrically-produced Plasmas
}

\author{
R. S. Lee, J Colvin, A. Frank, L. Fried, J. Reaugh and Bruce Remington
}

\begin{abstract}
The scope of the project was to conduct experimental and computer modeling studies of the launching, flight characteristics and impacts of thin flyer plates driven by laser ablation under drive conditions where the plate remains a solid and retains its strength. Motivation for the work was to provide the scientific underpinnings for advanced development work on new detonators that will be needed within the next ten years for use in the Laboratory's national security mission. Areas of study were to be coupling of laser energy into the flyer plate during the launch phase, melting and instability growth in the flyer during launch, and an explosive-grain-scale understanding of the shock-to-detonation transition when the flyer plate impacts an explosive target. Knowledge and modeling capability, developed from this study, were to enable us to tailor the launching and acceleration conditions of thin flyer plates to produce an optimum impact for initiating high explosives. Experimental and computational studies of the shock-to-detonation transition were to aid us in developing more efficient initiating explosives for use in future detonators.
\end{abstract}

\section{Technical Description}

Electrically driven slapper detonators have been used by the DOE since the mid1970 's. They have been intensively studied, both by experiments and by theoretical and numerical modeling. They operate by driving a thin dielectric plate to velocities of several $\mathrm{km} / \mathrm{s}$ by the electrical explosion of a thin foil. The shock wave produced when the thin dielectric plate (slapper) strikes an initiating explosive produces a reaction behind the shock front which transitions promptly to a detonation. More recently, initiation of explosives by laser-ablation-driven flyer plates has become a subject of interest. Such an initiation technique offers unprecedented safety because there are no natural optical sources that could produce an unintended initiation.

Thin flyer plates launched by laser ablation offer many interesting avenues for scientific investigation. The energy density of the laser pulses used for driving thin plates to initiate explosives is much lower than energy densities used for inertial confinement experiments, so it is of interest to test the optical absorption models at these lower energy densities. The acceleration of the flyer plates and the growth of instabilities also span a region of parameter space that has not received much attention, i.e. the flyer plate still has strength and the accelerations are much lower than in the inertial confinement experiments. We wished to experimentally study the acceleration of the plates and the

${ }^{*}$ This work was performed under the auspices of the U.S. Department of Energy by the University of California Lawrence Livermore national Laboratory under contract No. W7405-Eng-48. 
growth of instabilities seeded by spatial inhomogeneities in the laser beam and compare them with LASNEX calculations. Much of the information from the proposed study is also applicable to the launch, flight and impact of thin flyer plates driven by electrically heated plasmas and to the interaction of the impact-produced shock wave with explosives.

The shock waves from flyer plates of a few $\mu \mathrm{m}$ thickness are of such short duration that they are attenuated over a length scale comparable to the grain size of the initiating explosive. To understand the shock-to-detonation transition under such circumstances, we wished to characterize the impulse delivered to the explosive by the plate and the shape of the plate as it strikes the explosive. In addition, the dependence of the explosive response on pressure, pulse duration, shape of the flyer plate, and grain size of the initiating explosive were to be experimentally determined. The ALE3D hydrodynamic code was to be used with a grain-scale model of PETN to model the experimental results. Further theoretical work, centering on understanding the chemistry that occurs at very short pulse durations, was also planned.

\section{Experimental Work}

We began work on the project in mid fiscal year (April 2000). The project was proposed as a three-year activity, but was funded only through September 2000.

The first step in the experimental plan was to move the 10-J laser from the camera room for the 100-g firing tank in the High Explosives Applications Facility (HEAF) into the Micro-Detonics Facility ( $\mu \mathrm{DF}$ ) in HEAF, where most of the diagnostics that we planned to use for the project were available. This move involved considerable planning and paperwork before we could begin work. In particular, we needed to perform an engineering analysis on the capacitor discharge unit (CDU) which powers the flash lamps for the $10 \mathrm{~J}$ laser. The CDU, which stores $42 \mathrm{~kJ}$ of electrical energy at $18 \mathrm{kV}$, was located in the $100-\mathrm{g}$ tank room and was operated remotely from a control room. For the experiments we wished to perform in the $\mu \mathrm{DF}$, we needed to be able to fire the laser while we were in the same room. An engineering analysis was needed to assure ourselves that the operation was safe, in the event of an electrical explosion in the CDU.

The Integrated Work Sheet (IWS) giving permission to move the laser was submitted into the system on June 12 . On July 28 , the IWS was approved under the condition of additional safety modifications on the enclosure for the laser power supply. Installation of the laser also required modification of the room safety interlocks and additional electrical service in the room. While the work was being planned for moving the laser and the safety paperwork was being prepared, a large-aperture polarizer was installed on the laser to provide a uniform energy distribution in the beam. Work was also proceeding on a lowerreflectivity Fabry-Perot laser velocimeter, with a fill time of $\sim 300$ ps, to allow sub-ns, velocity-time measurements of the impulse delivered by laser-driven flyer plates when they impact a target. When the account was closed, work was nearly complete on the installation of the 10-J laser in the $\mu \mathrm{DF}$. 


\section{Calculations}

During the time we were moving the laser, calculations of flyer plate dynamics were proceeding, using the $2 \mathrm{D}$ radiation-hydrodynamics code LASNEX. The much different range of densities, temperatures, and physical processes for laser light absorption in the flyerplate-modeling problem required numerous additions to the code. Prescriptions were added for calculating the correct ionization state and electron densities for metals and insulators as a function of temperature and for the low-fluence absorption of the laser beam on the solid/liquid metal surface of the flyer. A photoionization absorption model was used to describe the absorption of the low-fluence laser beam; and a constitutive model for the material strength of the flyer was added. The new calculational model was tested using results from LLNL/Sandia experiments performed in 1994, where $25 \mathrm{~J} / \mathrm{cm} 2$ of $1.06-\mu \mathrm{m}$ laser light, in a 15-ns FWHM Gaussian pulse, was incident through a fused silica fiber onto aluminum foils of thickness $0.25 \mu \mathrm{m}, 1 \mu \mathrm{m}$, and $4 \mu \mathrm{m}$ [1], experiments reported by Trott in 1991 [2], and experiments on composite flyer plates reported by Labaste and co-workers in 1999 [3]. A simple Drude model approximated the initial absorption of the laser light in the skin-depth layer. With the changes and additions above, LASNEX was used to model various aspects of flyer plate launch. The results of these 1-D calculations were presented at the APS Division of Plasma Physics meeting in October 2000 [4].

The streak records reported in the 1994 experiments [1] showed that the laser pulse first melted and then completely ionized the $0.25 \mu \mathrm{m}$ and the $1 \mu \mathrm{m}$ flyer plates. These data allowed us to adjust the thermal parameters in LASNEX to correctly compute the arrival time of the melt and ionization fronts in the flyer plates at the front surfaces of the $0.25 \mu \mathrm{m}$ and the $1 \mu \mathrm{m}$ flyer plates.

The 1999 paper of Labaste and co-workers [3] reported experimental results for composite flyer plates consisting of a thin ablation layer, an insulating layer and a thicker, impactor layer. We wished to examine the effectiveness of the insulating layer, so in the calculations the flyer plate consisted of three layers: a $0.25-\mu \mathrm{m}$-thick $\mathrm{Al}$ ablative layer, $\mathrm{a}$ $0.25-\mu \mathrm{m}$ thick $\mathrm{Al}_{2} \mathrm{O}_{3}$ thermal barrier and a final $\mathrm{Al}$ layer of variable thickness. The $30 \mathrm{~ns}$ Gaussian laser pulse used in the calculations had an irradiance of $25 \mathrm{~J} / \mathrm{cm}^{2}$. The calculational results demonstrated the effectiveness of the insulating layer. Without it, the flyer plate melted in $35 \mathrm{~ns}$ instead of $70 \mathrm{~ns}$. Melt can also be delayed by increasing the ablator thickness. For a $0.5 \mu \mathrm{m}$ ablator the melt is delayed to $85 \mathrm{~ns}$ while reducing the flyer velocity by only $5 \%$.

The 1991 paper of Trott [2] reported velocities of laser-driven flyer plates as a function of irradiance. From these data we estimated a maximum velocity of about $4 \mathrm{~km} / \mathrm{s}$ for the flyer plate geometry and laser fluence used in the calculations. The calculational results, shown in Fig 1, were in good agreement with the reported values. 
flyer trajectory (um) vs time (ns)

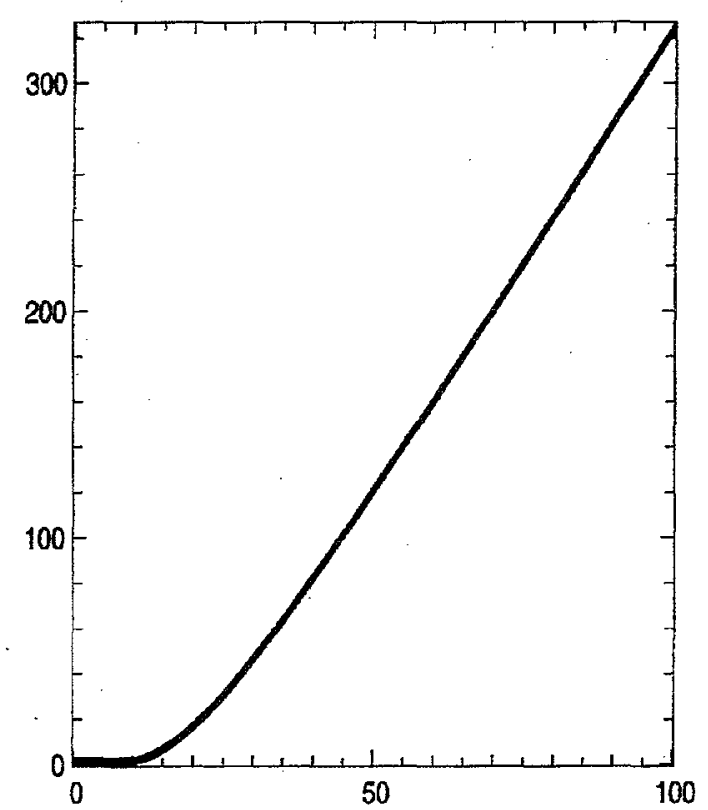

flyer velocity (um/ns) vs time (ns)

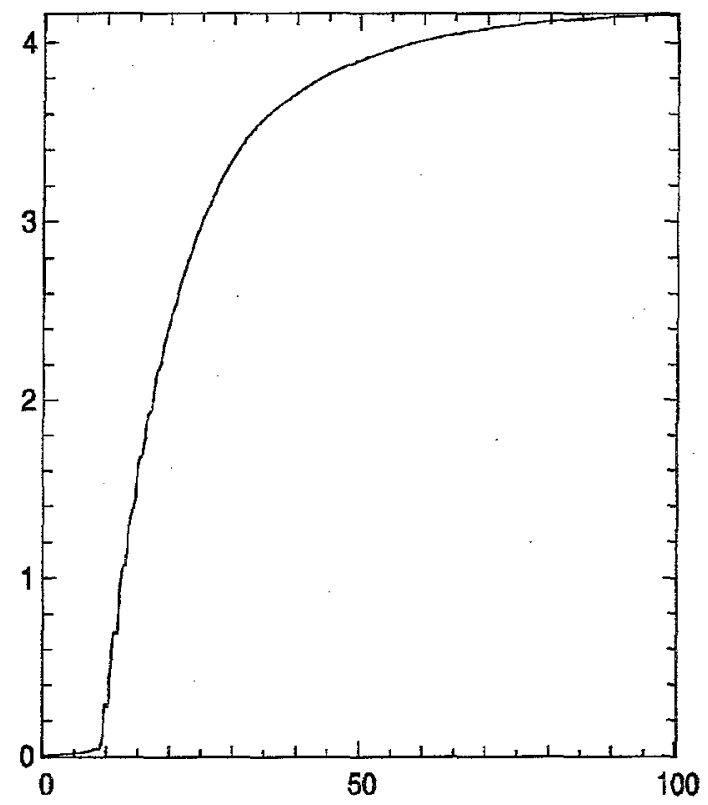

Figure 1. LASNEX, 1-D calculations of distance-time and velocity-time curves for a thin Al plate driven by laser ablation.

The LASNEX calculations gave us some new insights into the process of launching a thin flyer plate using laser ablation. We found little sensitivity in the calculations to insulator band gap energy and metal reflectivity at high-temperatures but there was some sensitivity to metal reflectivity at low temperature. The sensitivity to the initial reflectivity of the metal being ablated has also been reported by Labaste and co-workers [3]. Thermal conduction from metal-vapor into the substrate boils away some of the glass substrate, adding to the pressure driving the flyer, enhancing flyer velocity by $\sim 25 \%$. This raises the interesting question of whether the substrate material properties could be used in optimizing a laser driver system for flyer plates.

Calculations of temperature profiles gave more insight into the role that is played by the thermal barrier. A typical flight distance in the 1994 study was $\sim 100 \mu \mathrm{m}$, corresponding to a flight time of about $40 \mathrm{~ns}$ from the curves shown in Fig. 1. Figure 2 shows the temperature vs. time at an interior point in the flyer and temperature vs. position at 50 and 70 ns after the start of the laser pulse. Without the thermal barrier, the calculation predicts full flyer melt in $35 \mathrm{~ns}$, but with the barrier in place melt does not occur until $70 \mathrm{~ns}$. Melt is highly undesirable if one wishes the flyer plate to stay intact until impact and the computational model offers a means for optimizing the thickness of the thermal barrier. Had the project continued, our plan was to use the 1-D code to optimize the model to fit a wider range of more precise data and ultimately to use the model parameters in a 2-D calculation 
where we would seek the launch conditions which would minimize instability growth while

\section{Simulated temperature in microflyer (eV)}
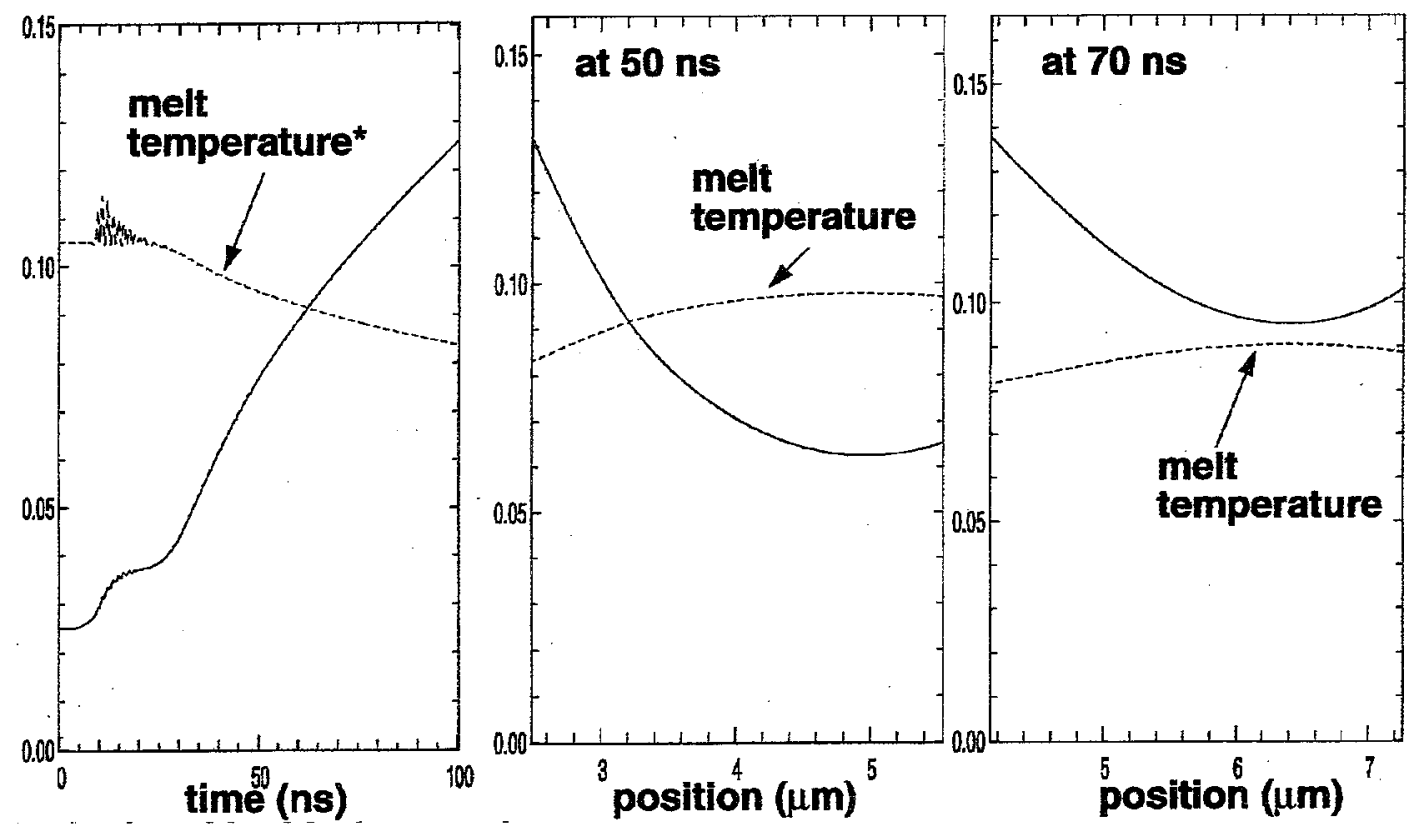

maximizing flyer kinetic energy and impact impulse.

Figure 2. The panel on the left shows the temperature vs. time at an interior point in the flyer. The other two panels show the temperature as a function of position in the flyer at 50 and $70 \mathrm{~ns}$ after the start of the laser pulse.

\section{Summary and Conclusions}

The goal of the project was to conduct experimental and computer modeling studies of the launching, flight characteristics and impacts of thin flyer plates driven by laser ablation under drive conditions where the plate remains a solid and retains its strength. Motivation for the work was to provide the scientific underpinnings for advanced development work on new detonators that will be needed within the next ten years for use in the Laboratory's national security mission. Areas of study were to be coupling of laser energy into the flyer plate during the launch phase, melting and instability growth in the flyer during launch, and an explosive-grain-scale understanding of the shock-to-detonation transition when the flyer plate impacts an explosive target. Knowledge and modeling capability developed from this study were to enable us to tailor the launching and acceleration conditions of thin flyer plates to produce an optimum impact for initiating high explosives. Experimental and computational studies of the shock-to-detonation transition were to aid us in developing more efficient initiating explosives for use in future detonators.

Because of the very limited time for which the project was funded (April-September), we were unable to fully achieve any of the goals. On the experimental side, most of the 
effort went into moving the 10-J laser into the Microdetonics Laboratory, generating the necessary paperwork for operation in the new location and integrating the laser system into the room safety interlock system. We also modified the enclosure for the CDU to protect experimenters in the unlikely event of an electrical breakdown and explosion. A largeaperture polarizer was installed on the laser to provide a uniform energy distribution in the beam. Work was also proceeding on a lower-reflectivity Fabry-Perot laser velocimeter, with a fill time of $\sim 300 \mathrm{ps}$, to allow sub-ns, velocity-time measurements of the impulse delivered by laser-driven flyer plates when they impact a target.

One-dimensional LASNEX calculations were performed to benchmark the model parameters before extending the calculations to two dimensions. The initial calculations gave reasonable agreement with the data and interesting insights into the flyer launch process. More experimental data and 1-D calculations are needed before the model parameters can be used with confidence for modeling studies of flyer launch at the irradiances of interest to us. The grain-scale modeling of HE initiation required experimental data, which we could not yet provide, so no significant effort was expended in this area.

\section{References}

[1] A. M Frank and W. M. Trott, Stop motion photography of laser-driven plates, SPIE Proc. Symp. on Ultrahigh- and High-Speed Photography, Videography and Photonics '94, Vol 2273, pp 196-206 (1994).

[2] W. M. Trott, Laser-driven flyer acceleration using optical fiber coupling, Shock Compression of Condensed Matter - 1991, Schmidt, et al. ed., pp 829-832, Elsevier Science, New York (1992).

[3] J. L. Labaste, M. Doucet, D. Brisset, Initiation optique: optimisation de la mise en vitesse d'un projectile initie par laser, Proc. $7^{\mathrm{e}}$ Congrès International de Pyrotechnie, pp 497-507, Association Française de Pyrotechnie, La Ferté-St-Aubin, France (1999).

[4] J. D. Colvin, A. M. Frank, R. S. Lee, and B. A. Remington, Numerical simulations of laser-driven flyer plates, Paper \#JP.051, APS Div. of Plasma Physics Meeting, Quebec City, October 2000. 